\title{
Perinatal and maternal outcome in advanced maternal age, more than or equal to 35 years: a prospective observational study
}

\author{
Deepti Nagendra Prasad*, Beena Madhavth
}

Department of Obstetrics and Gynaecology, Bhabha Atomic Research Centre, Chembur, Mumbai, Maharashtra, India

Received: 18 December 2020

Revised: 12 January 2021

Accepted: 13 January 2021

\section{*Correspondence:}

Dr. Deepti Nagendra Prasad,

E-mail: docdeeptiprasad@gmail.com

Copyright: ( $)$ the author(s), publisher and licensee Medip Academy. This is an open-access article distributed under the terms of the Creative Commons Attribution Non-Commercial License, which permits unrestricted non-commercial use, distribution, and reproduction in any medium, provided the original work is properly cited.

\begin{abstract}
Background: As there is increasing trend with pregnancy being delayed due to various reasons, this topic was studied so as to help patient and health care provider know the effect of advanced age on pregnancy and its outcome both related to mother and fetus. The objective of the study was to evaluate maternal and perinatal outcome in advanced maternal age in terms of fetal outcome, maternal outcome and labour outcome.

Methods: 102 pregnant patients of age 35 years and more over 1 year from November 2015 to October 2016 in Holy family hospital, Bandra, Mumbai.

Results: Incidence of hypertensive disorders, malpresentation, rate of conception on treatment and caesarean section is more in advanced maternal age.

Conclusions: A proper pre-conceptional consultation and intensive antenatal care assessment can reduce the risks in advanced maternal age pregnancy.
\end{abstract}

Keywords: Advanced maternal age, Hypertensive disorders, GDM

\section{INTRODUCTION}

Advanced maternal age, defined as age 35 years and older at estimated date of delivery. ${ }^{1}$ There is a growing trend for child bearing to occur later in women's lives. Over the past four decades, there has been a dramatic increase in the number of women having their babies at age 35 and older.

Reasons to postpone child-bearing reflect the availability of safe, effective and reversible contraception, which has allowed women the reproductive autonomy to decide if and when they will have children. In pursuit of higher education and career advancement outside the home, delayed marriage, increased rate of divorce followed by remarriage all contribute to this upward trend. In a developing country like India, this trend is sometimes because of multiparity in view of male child and poor acceptance of contraceptive method. ${ }^{2}$
With increasing age, fertility and the chance of getting pregnant is reduced, beginning slowly in early thirties and speeding up in late thirties and forties. As female is born, she is born with all of the ova she will ever have, so with age, there is decrease in number and quality of ova remaining. ${ }^{3}$

With age, there is decreases in fecundity with increase in risk of miscarriage, spontaneous abortion, pregnancy complications, and adverse pregnancy outcomes (including pre term delivery and multiple birth) increases. Also with age, many opt for fertility treatment to improve their chance of conception. ${ }^{4}$ Women should be made aware of the risks so that they make informed decision about their pregnancy including when to become pregnant and here is role of preconceptional counselling.

The risk of having a Down's syndrome baby rises with maternal age, essentially doubling from 1 in 725 at 
maternal age 32 to 1 in 365 at maternal age 35 . This risk continues to climb and is 1 in 32 at maternal age $45 .^{5} \mathrm{~A}$ higher incidence of hypertensive disorders in older women were reported in many studies. ${ }^{6}$ Advancing maternal age is associated with an increased prevalence of twin pregnancy, related to both a higher rate of naturally conceived twins and a higher use of ART in older women. Caesarean section increases with age, reasons include an increased prevalence of medical complications, fetal malposition, cephalopelvic disproportion, induction of labour, a failed trial of labour, and uterine rupture, precious pregnancy, multiple pregnancies. ${ }^{8}$

\section{Aim and objectives}

The aim and objectives of this study is to evaluate maternal and perinatal outcome in advanced maternal age in terms of:

\section{Fetal outcome}

Congenital malformations, chromosomal anomalies, still birth, NICU admission, birth asphyxia, low birth weight, macrosomia, preterm babies, low Apgar score, morbidity, mortality and others.

\section{Maternal outcome}

\section{Medical complications}

Gestational hypertension, gestational diabetes mellitus, anemia, fibroid and others.

\section{Pregnancy complications}

Malpresentation, ante partum hemorrhage, post partum hemorrhage, ectopic pregnancy, abortion, intra uterine growth retardation and others.

\section{Labor outcome}

\section{Mode of delivery}

Normal delivery, forceps delivery, vacuum delivery and caesarean section.

\section{Labor complications}

Preterm labor, prolonged labor, PROM and others.

\section{METHODS}

\section{Study type}

Observational prospective study.

\section{Study place}

Department of Obstetrics and Gynaecology, Holy Family Hospital, Bandra (West), Mumbai (Maharashtra, India).

\section{Study period}

November 2015 to October 2016.

\section{Study population}

102 pregnant patients more than or equal to 35 years admitted in labour room for delivery or safe confinement of pregnancy in Holy Family Hospital, Bandra.

\section{Inclusion criteria}

All parity pregnant women with age more than or equal to 35 years at delivery. Singleton/ Multiple pregnancy. Conceived spontaneously or after treatment. Pre existing medical or surgical conditions.

\section{Exclusion criteria}

Patients who refused to give consent to participate in the study.

\section{Procedure}

Study was started after Ethical Committee approval.

102 pregnant patients of age 35 years and more were selected during one year from November 2015 to October 2016.

Only those patients who fulfilled the inclusion criteria were enrolled. Signature and consent of the patients were taken at the time of study. At any point of the study if the patient fell short of the inclusion criteria she was omitted from the study and the next patient taken.

Patients admitted in Holy Family Hospital were included in the study. Each one of them was evaluated by detailed history which include the menstrual, obstetric and clinical examination.

Patients were followed up once monthly till 28 weeks, once fortnightly till 36 weeks and weekly there after till term. Minimum three to four visits were necessary. More frequent visits in high risk pregnancies like gestational hypertension, GDM, diabetes mellitus, primary infertility etc. were observed for effect of advance maternal age on fetal growth closely.

Patients who had registered in the first trimester were subjected to USG for NT and NB scan and dual marker biochemical study. In the second trimester or those who registered in the second trimester (before 20wk) were subjected to malformation (anomaly) scan, triple marker or quadruple biochemical screening. After 20 weeks of gestations, only malformation scan was done. Patients showing high risk in above screening test, were subjected to do amniocentesis. 
Perinatal outcome recorded in terms of birth weight, any chromosomal abnormalities (anencephaly, spina bifida, cyanotic congenital heart disease, congenital diaphragmatic hernia, omphalocoele, gastroschisis, limb reduction defect, cleft lip with cleft palate, cleft palate, Down syndrome, suspected chromosomal disorder, and hypospadias) gestational age of delivery, NICU admission, causes of NICU admission and NICU course.

Maternal outcome recorded in terms of mode of obstetric complication, systemic complications. Labour outcome in terms of mode of delivery and labour complications noted.

\section{Statistical analysis}

Sample size calculation SAS 9.2 software.

The proposed sample size for in a tertiary care centre will require minimum of 102 patients with $\mathrm{H} 0$ : 20\% (Ref.) $\mathrm{H} 1: 10 \%$ with power of $90 \%$ and alpha $=0.05$. The formula used is $\mathrm{Z}$ test for binomial proportion.

\section{RESULTS}

\section{Distribution of cases as per maternal age}

Out of 102 cases, maximum patients were of 35 years age $(34.30 \%)$ followed by 36 years age $(20.6 \%)$.

\section{Distribution of cases as per education level}

Most of our patients had education till graduation or above (70.6\%), while only about $1 \%$ had no formal education.

\section{Distribution of cases as per occupation}

$68.60 \%$ cases were home makers as against $31.40 \%$ working class.

\section{Distribution of cases according to medical or surgical co- morbidities}

Maximum cases were without previous medical or surgical co-morbidities (70.58\%). 12 cases out of 102 had thyroid disorders. 11 cases had other co-morbidities which included 5 cases of PCOD, 2 cases of $\mathrm{Rh}$ negative pregnancy, 1 case of $\mathrm{HbsAg}$ positive status, 1 case of bariatric surgery, 1 case of ?? breast malignancy, 1 case of psoriatic arthritis. 7 cases had more than one medical disorder - 2 had asthma+ PCOD, one each had TB+ PCOD, HTN+ PCOD, thyroid disorder+ PCOD, thyroid disorder+ asthma, DM+ HTN.

\section{Distribution of cases according to gravida}

Out of 102 cases, 26 patients were primigravida and 76 were multigravida.
Table 1: Distribution of cases according to mode of conception.

\begin{tabular}{|ll|}
\hline Mode of Conception & Percentage \\
\hline Spontaneous & 90.20 \\
\hline On Treatment & 9.80 \\
\hline
\end{tabular}

Out of 102 cases, 92 cases, i.e., $90.20 \%$ had spontaneous conception and 10 cases i.e. $9.8 \%$ conceived after treatment.

Amongst 10 cases who conceived after treatment, 6 cases underwent IUI, 2 cases conceived after IVF, 1case after ovulation induction and 1 case after ICSI.

Table 2: Distribution of cases according to onset of labour.

\begin{tabular}{|ll|}
\hline Onset of Labour & Percentage \\
\hline Absent & 38 \\
\hline Spontaneous & 38 \\
\hline Induced & 24 \\
\hline
\end{tabular}

Out of 92 cases who delivered (excluding 10 cases of abortions), 35 cases didn't undergo in labor as they were electively taken up for LSCS. 35 cases went in spontaneous labor. In 22 cases, labor was induced.

Table 3: Distribution of cases according to maternal medical complications.

\begin{tabular}{|ll|}
\hline Maternal medical complications & Percentage \\
\hline Nil & 71.70 \\
\hline GDM & 2.10 \\
\hline PIH & 16.30 \\
\hline Anemia & 4.30 \\
\hline Fibroid & 4.30 \\
\hline Others & 2.10 \\
\hline
\end{tabular}

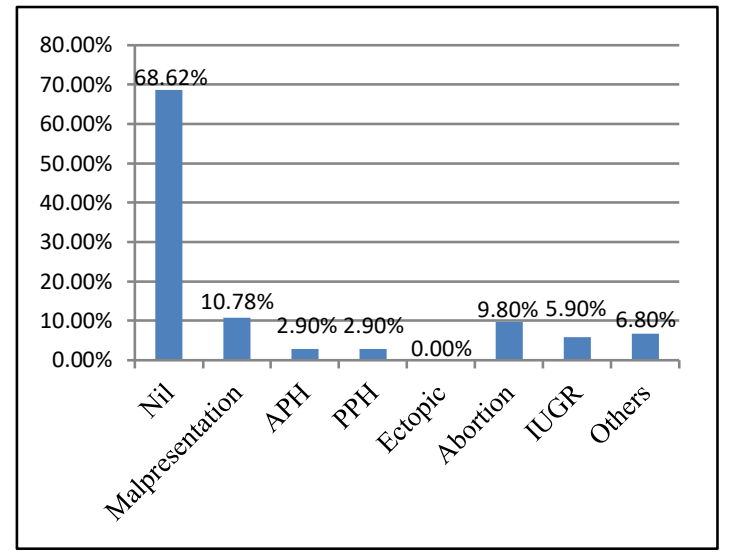

Figure 1: Distribution of cases according to pregnancy related complications. 
Out of 92 cases who delivered (excluding 10 cases of abortions), 66 cases, i.e., $71.70 \%$ had no maternal medical complications.

2 cases had GDM, 15 cases had PIH, 4 cases had anemia and 4 cases had Fibroid. 2 cases had other complications which included 1 case of bad obstetric history and 1 case of ovarian cyst.

4 cases had combination of these complications.

Out of 102 cases, 70 had no pregnancy related complications.

11 cases had malpresentation, 3 had APH (placenta previa), 3 had PPH, 6 had IUGR.

There were 10 cases of abortions of which 2 were incomplete abortion, 7 missed abortion and 1 blighted ovum.

7 had other complications which included 4 cases of Incompetent Os, 2 cases of polyp and 1 case of ICU admission.

There were 5 cases with combination of these complications.

Table 4: Distribution of cases according to fetal complications.

\begin{tabular}{|ll|}
\hline Fetal Complications & Percentage \\
\hline Nil & 72.82 \\
\hline Low Birth Weight & 17.40 \\
\hline Preterm Baby & 8.70 \\
\hline Birth Asphyxia & 9.80 \\
\hline Still Birth & 0.00 \\
\hline Congenital Anomalies & 3.20 \\
\hline Others & 4.30 \\
\hline
\end{tabular}

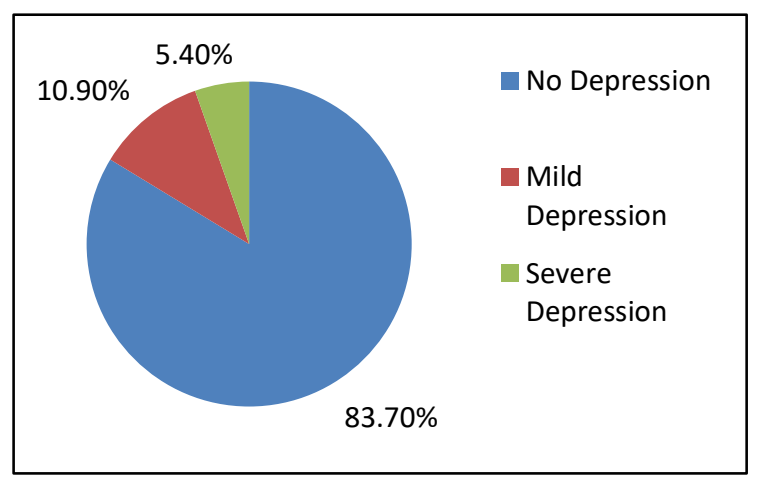

Figure 2: Distribution of cases according to APGAR score.

Out of 92 cases who delivered (excluding 10 cases of abortions), 67 cases, ie, $72.82 \%$ had no fetal complications. 16 cases had low birth weight babies.
8 cases had preterm babies. 9 cases had babies with birth asphyxia.

3 babies had congenital anomalies (meningomyelocele, hydrops fetalis and Downs syndrome)

4 cases had babies with other complications which included cases of meconium stained amniotic fluid, brachial plexus injury and macrosomia.10 cases had combination of fetal complications.

Out of 92 cases who delivered (excluding 10 cases of abortions), $77(83.70 \%)$ cases delivered babies with no depression in APGAR score.

10 cases had mild and 5 cases had severe depression.

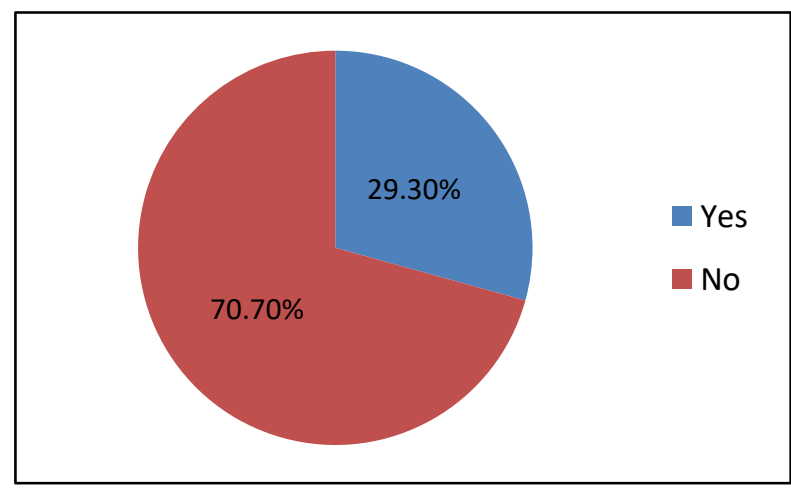

Figure 3: Distribution of cases according to NICU admission.

Out of 92 babies born (excluding 10 cases of abortions), 65 babies, i.e., $70.70 \%$ didn't require NICU admission while 27 babies, i.e., $29.30 \%$ required NICU admission. Of 27 NICU admissions, maximum, i.e., 12 were due to preterm and LBW.

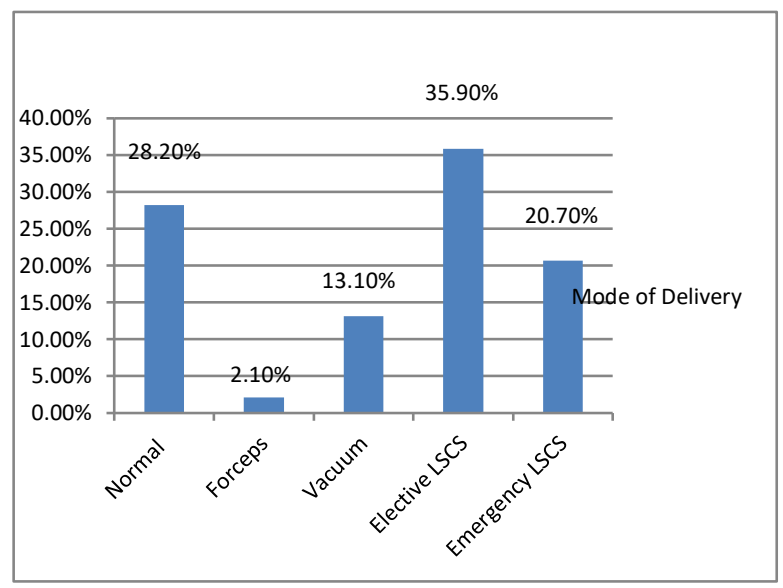

Figure 4: Distribution of cases according to mode of delivery.

Amongst 92 cases who delivered, 26 cases, i.e., $28.2 \%$ underwent normal delivery. 
2 cases underwent forceps and 12 cases underwent vacuum delivery. 33 cases had elective LSCS and 19 cases underwent emergency LSCS.

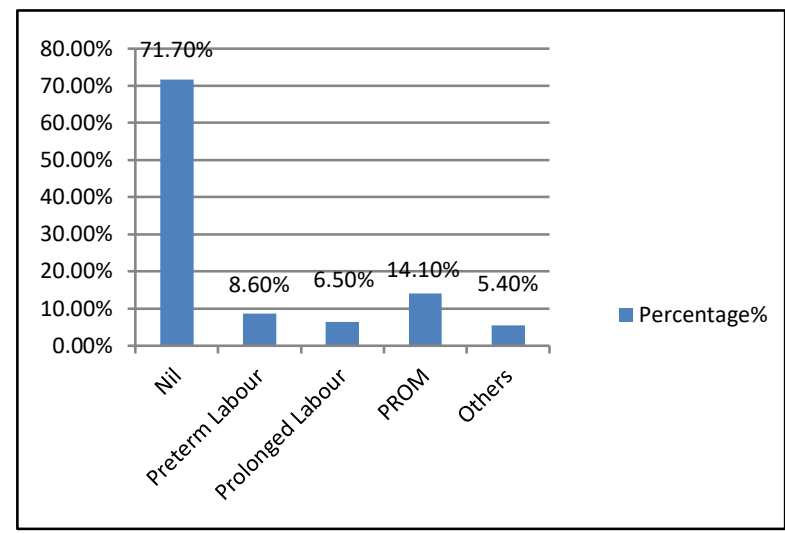

Figure 5: Distribution of cases according to labour complications.

Out of 92 cases who delivered, 66 cases, i.e., $71.70 \%$ had no labor complications.

8 cases had preterm labor, 6 cases had prolonged labor, 13 cases had PROM and 5 cases had other complications like perineal and cervical tear. 5 cases had combination of complications.

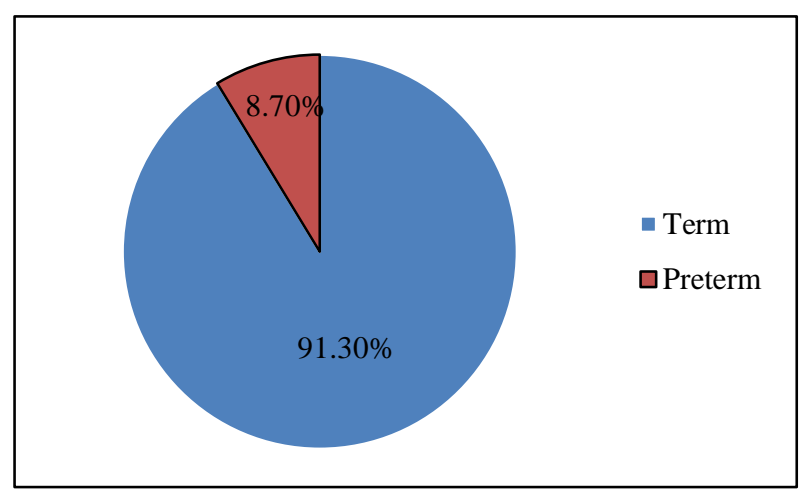

Figure 6: Distribution of cases as per term and preterm deliveries.

\section{DISCUSSION}

The present study was done in a teaching hospital in Western Mumbai.

As the trend of pregnancy in advanced maternal age is increasing nowadays, this study was taken up.

In our study, maximum number of cases were of age group between $35-40$ years $(90.1 \%)$ with only $8.7 \%$ cases between $40-45$ years and only $1 \%$ of the study group was $>45$ years.

Our centre being a private hospital, most of our patients were from middle or upper socioeconomic class, had education upto graduation or above $(70.6 \%)$ and $31.40 \%$ were belonging to working class.

In our study, 10 cases out of 102 conceived after treatment of which 6 cases underwent IUI, 2 cases after IVF and 1 case each after ovulation induction and ICSI. Results in our study are comparable to study done by Pawde at Jehangir Hospital where amongst $>35$ years, $12.6 \%$ cases conceived after treatment as compared to $3.5 \%$ cases of $<35$ years age group. ${ }^{9} 24 \%$ patients conceived after treatment in study carried out by Pallavi S Kalewad at Nowrosjee Wadia Maternity Hospital, Parel, Mumbai. ${ }^{10}$

$70.58 \%$ cases in our study had no medical or surgical comorbidities. $11.76 \%$ had thyroid disorders, others included chronic hypertension $(5.80 \%)$, diabetes mellitus $(0.98 \%)$, TB $(0.98 \%)$ and asthma $(5.88 \%)$. Remaining conditions like PCOD, Rh negative pregnancy etc were seen in $10.70 \%$ of the cases including few cases who had overlapping disorders.

A study conducted in 2015 on prevalence of thyroid dysfunction among women during the first trimester of pregnancy at a tertiary care hospital in Haryana by Rajput et al found that incidence of hypothyroidism is $22.77 \%$ in his study. ${ }^{11}$

In our study, incidence of hypertensive disorder of pregnancy was $22.10 \%$ of which gestational hypertension was $16.30 \%$ and $5.8 \%$ had chronic hypertension. These findings are comparable to a prospective observational study done by Pawde et al at Jehangir Hospital April 2015 which had incidence of hypertensive disorders as $7.23 \%$ in $<35$ years age group and $17.54 \%$ in $>35$ years age group. 9 The incidence was lower as compared to retrospective comparative study conducted by Sahu T Meenakshi et al in Queen Mary's Hospital, King George Medical University, Lucknow in 2007 had incidence of PIH as $29.4 \%$ in $>35$ years as against $16.4 \%$ in less than 35 years. ${ }^{12}$ The incidence was low compared to prospective comparative study carried out by Giri et al in department of obstetrics and gynecology at Nepal Medical College and Teaching Hospital over the period of one year from October 2012 to September 2013 had incidence of PIH $26.6 \%$ in $>35$ years and $4.4 \%$ in $<35$ years. ${ }^{13}$ The lower incidence of hypertensive disorders in our study can be explained by our hospital being situated in western Mumbai with majority of cases being educated, had early and regular visits in hospital during pregnancy so early detection of the cases.

With increasing age, incidence of diabetes also increases. Our study showed an incidence of diabetes mellitus of $1 \%$ and GDM of $2 \%$ which is lower as compared to study by Pawde at Jehangir hospital where incidence of GDM as $6.43 \%$ in $<35$ years age group as compared to $10.52 \%$ in $>35$ years age group and also lower compared to study by Meenakshi et al at K.G.M.U, Lucknow in 2007 which had incidence of DM $4.1 \%$ in $>35$ years as compared to $0.7 \%$ in $<35$ years. ${ }^{9,12}$ A retrospective analysis of data by Jolly 
et al from 3,85,120 singleton pregnancies in the North West Thames Region, UK, between 1988 and 1997 concluded that pregnant women aged 35-40 years were at increased risk of gestational diabetes. ${ }^{14}$

Benli et al in their study in Vakif Gureba Training and Research Hospital, Clinic of Obstetrics and Gynecology in 2006 on effect of maternal age on pregnancy outcome and Cesarean delivery rate found that ratio of GDM was $6.5 \%$ in the study group and was $3.4 \%$ in the control group. ${ }^{15}$

The lower incidence of GDM in our study could be due to small sample size as compared to other studies.

With increasing age, incidence of malpresentation also increases due to uterine fibroid and poor abdominal muscle tone. Our study had $4.30 \%$ incidence of fibroid and $10.78 \%$ incidence of malpresentation which is higher than study by Giri et al at Nepal Medical College where incidence of breech was $1.1 \%$ in $<35$ years age group as against $8.8 \%$ in $>35$ years age group.13 Another retrospective comparative study conducted in Department of Public Health, University of Limpopo (Medunsa Campus), South Africa from 1st September to 30th November 2010 had incidence of breech as $7 \%$ in $>35$ years as compared to $3.9 \%$ in $<35$ years. ${ }^{16}$

The increasing rate of Ceasarean section in aged women are claimed to be because of many reasons including medical diseases, pregnancy complications or fetal problems. In our study, incidence of Ceasarean section was $56.6 \%$, of these $35.90 \%$ were elective amongst which most common indication was previous $\operatorname{LSCS}(63.63 \%)$ and $20.70 \%$ were emergency LSCS. Common indications for emergengy LSCS were non progress of labour and other causes like fetal distress, PROM or combination of these. Study conducted in Nowrosjee Wadia Maternity Hospital, Parel by Pallavi S Kalewad had incidence of LSCS as $68 \% .{ }^{10}$ Findings in our study are slightly higher than in study at K.G.M.U by Meenakshi et al where incidence of LSCS was $48.9 \%$. Study at Jehangir hospital by Pawde had incidence of LSCS as $35.2 \%$ in $>35$ years as compared to $25.5 \%$ in $<35$ years cases and most common indication of LSCS was previous LSCS same as in our study.9 Another prospective comparative study at Nepal Medical College had incidence of LSCS as $28.8 \%$ in $>35$ years group as against $17.7 \%$ in $<35$ years group. 12 Study by Benli in 2015 had Caesarean delivery rate as $46.1 \%$ in study group in a period of 1 year. However, Caesarean delivery rate was $40.9 \%$ in the control group. Caesarean delivery rate was found as $31.6 \%$ in all the deliveries. The most common cause of Caesarean section indication was fetal distress in advanced maternal age $(11.7 \%)$, whereas previous Caesarean section was found as the most common cause in the control group $(15.1 \%){ }^{15}$

With higher incidence of multiple gestation and underlying medical disorder, risk of preterm delivery and low birth weight increases. In our study, incidence of preterm delivery was $8.70 \%$ and low birth weight was
$17.40 \%$ which was lower than study at Jehangir hospital where incidence of preterm delivery was $17.5 \%$ in $>35$ years as against $10.3 \%$ in $<35$ years. ${ }^{9}$ Study at Department of Public Health, Limpopo South Africa had incidence of preterm delivery as $19.2 \%$ in $>35$ years as against $14.7 \%$ in <35 years and incidence of low birth weight as $27.9 \%$ in $>35$ years as against $18.8 \%$ in $<35$ years. ${ }^{16}$ Study conducted in Nowrosjee Wadia maternity hospital, Parel, Mumbai had incidence of preterm delivery as $23.7 \%$ and low birth weight baby as $42.8 \%$ which is higher than our study. ${ }^{10}$

Our centre being situated in western Mumbai with majority of cases from middle or upper socio-economic status and they being educated, had frequent antenatal check up with early detection and treatment of any pregnancy complication, the pregnancy and fetal outcomes were better as compared to other studies.

Incidence of NICU admission in our study was $29.3 \%$ comparable to study at Nowrosjee Wadia maternity hospital, Parel, Mumbai which had incidence of NICU admission as $33 \% .^{10}$

Most of the admissions in NICU were due to preterm deliveries and low birth weight $(44.44 \%)$ which is also the indication in many other studies.

Incidence of abortion in our study is $9.8 \%$ which is lower than study at Jehangir hospital which had $18.9 \%$ incidence of abortion and early pregnancy loss. ${ }^{9}$

Incidence of placenta previa in our study was $2.95 \%$ comparable to finding in a study at Jehangir hospital where it was $1.75 \%{ }^{9}$

Study by Nasreen at Khyber teaching hospital, Peshawar demonstrated that advancing maternal age is associated with progressively elevated risk of placenta previa. However, the maximum number of patients $(39 \%)$ were more than 35 years old, while $2 \%$ of patients were less than 20 years old.

Study by Hussain in 2004 showed that development of lower segment placenta has relation with increased number of gravidity and maternal age. ${ }^{18}$

Fortunately, there was no still birth in our study and no maternal mortality.

\section{CONCLUSION}

A proper pre-conceptional consultation and intensive antenatal care assessment can individualize and potentially reduce the risks for women considering a pregnancy at any meternal age. The rising trend of obstetric complications were observed in patients $>35$ years of age so this group of patients should be considered as one of the obstetric high risk category and they need special attention and vigilant care in the multidisciplinary tertiary care centre. 
With higher incidence of chromosomal abnormilities, women $\geq 35$ years of age should be offered screening for fetal aneuploidy. With availability of noninvasive, sensitive biochemical tests in combination with nuchal scan, need for invasive procedures has greatly reduced. Since these women are at higher risk of complications compared to the younger group, they should be advised to adhere to frequent antenatal visits and should be kept under close supervision of a senior obstetrician. Increased maternal and fetal surveillance will ensure a better perinatal outcome.

\section{Recommendations}

Pregnancies at advanced maternal age are at higher risk for complications, so adequate pre-conceptional, frequent antenatal and optimal neonatal care helps in improving the outcome. We also recommend a further multicentric long term studies including all the government and private hospitals at district and sub district level to know the exact magnitude of problems. As biochemical markers helps in detection of anomalies, its recommended to be subsidized by the government so that it can reach masses. We also suggest all tertiary level centres, referral hospitals, state, regional and national obstetric societies to maintain a register of pregnancies in advanced maternal age, so that the data can help us understand the gravity of problem, our lacuna in healthcare delivery and help us provide better obstetric care.

\section{Funding: No funding sources}

Conflict of interest: None declared

Ethical approval: The study was approved by the Institutional Ethics Committee

\section{REFERENCES}

1. Usta IM, Nassar AH. Advanced maternal age. Part I: obstetric complications. American journal of perinatology. 2008;25(08):521-34.

2. Mensch BS, Singh S, Casterline JB. Trends in the timing of first marriage among men and women in the developing world. The changing transitions to adulthood in developing countries: Selected studies. 2005;118-71.

3. Johnson JA, Tough S. Delayed child-bearing. J Obstetr Gynaecol Canada. 2012;34(1):80-93.

4. Karabulut A, Ozkan S, Bozkurt AI, Karahan T, Kayan S. Perinatal outcomes and risk factors in adolescent and advanced age pregnancies: comparison with normal reproductive age women. J Obstetr Gynaecol. 2013;33.

5. Aboneaaj M. The Association of Advanced Maternal Age and Adverse Pregnancy Outcomes. 2015.
6. Jacobsson B, Ladfors L, Milsom I. Advanced maternal age and adverse perinatal outcome. Obstetrics and Gynecology. 2004;104(4):727-33.

7. Multiple Pregnancy and Birth: Twins, Triplets, and High-order Multiples A Guide for Patients Revised 2012, American Society of Reproductive Medicine 1209 Montegmory Higghway Birmingham, Alabama. 2012;35216-2809(205):978-5000.

8. Callaway LK, Lust K, McIntyre HD. Pregnancy outcomes in women of very advanced maternal age. Australian and New Zealand journal of obstetrics and gynaecology. 2005;45(1):12-6.

9. Anuya A. Pawde, Manjiri P. KulkarniJyothi Unni, Pregnancy in Women Aged 35 Years and Above: A Prospective Observational study, The Journal of Obstetrics and Gynecology of India. 2015;65(2):93-6.

10. Kalewad PS, Nadkarni T. The perinatal and maternal outcome in pregnancy with advanced maternal age 35 years and $>35$ years. International Journal of Reproduction, Contraception, Obstetrics and Gynecology. 2016;5(6):1929-35.

11. Rajput R, Goel V, Nanda S, Rajput M, and Seth S. Prevalence of thyroid dysfunction among women during the first trimester of pregnancy at a tertiary care hospital in Haryana, Indian $\mathrm{J}$ Endocrinol Metab. 2015;19(3):416-19.

12. Meenakshi ST, Anjoo A, Vinita D. J Obstet Gynecol India. 2007;57(4):320-23.

13. Giri A, Srivastav VR, Suwal A, Tuladhar AS. Advanced maternal age and obstetric outcome. Nepal Med Coll J. 2013;15(2):87-90.

14. Jolly M, Sebire N, Harris J, Robinson S, Regan L. The risks associated with pregnancy in women aged 35 years or older. Human reproduction. 2000;15(11):2433-7.

15. Benli AR, Benli NC, Usta AT, Atakul T, Koroglu M. Effect of Maternal Age on Pregnancy Outcome and Cesarean Delivery Rate. Journal of clinical medicine research. 2015;7(2):97.

16. Hoque ME. Advanced maternal age and outcomes of pregnancy: A retrospective study from South Africa. Biomedical Research. 2012;23(2):281-5.

17. Tarney CM. When Patients Request the KnifeCesarean Delivery on Maternal Request. J Womens Health. 2014;1(3):2.

18. Hossain GA, Islam SM, Mahmood S, Chakraborty RK, Akhter N, Sultana S. Placenta previa and it's relation with maternal age, gravidity and cesarean section. Mymensingh Med J: MMJ. 2004;13(2):1438 .

Cite this article as: Prasad DN, Madhavth B.

Perinatal and maternal outcome in advanced maternal age, more than or equal to 35 years: a prospective observational study. Int J Reprod Contracept Obstet Gynecol 2021;10:696-702. 